\title{
Occurrence of Ploidy Shift in a Strain of the Imperfect Yeast Candida albicans
}

\author{
By TAKAHITO SUZUKI, ${ }^{*}+$ TOSHIO KANBE, ${ }^{1}$ \\ TSUNEYOSHI KUROIWA ${ }^{2}$ AND KENJI TANAKA ${ }^{1}$ \\ ${ }^{1}$ Laboratory of Medical Mycology, Research Institute for Disease Mechanism and Control, \\ Nagoya University School of Medicine, Nagoya 466, Japan \\ 2 Department of Cell Biology, National Institute for Basic Biology, Okazaki 444, Japan
}

(Received 25 June 1985; revised 24 September 1985)

\begin{abstract}
A clinical isolate of Candida albicans, a member of the Fungi Imperfecti, was polyploid as shown by the fact that it contained two kinds of nuclei, one of diploid and one of tetraploid DNA content. These determinations were made by fluorescence microscopy-photometry. The nucleus-associated organelles (NAOs), or spindle pole bodies, of yeast cells in this isolate were classified into two groups, one diploid and the other tetraploid, according to their dimensions as determined by serial thin-sectioning electron microscopy. A ploidy shift from diploid to tetraploid was found in individual cells of a culture of this isolate undergoing diphasic growth in minimal salts medium. A process of shift-down or reduction of ploidy from tetraploid to diploid was also observed by electron microscopy during these growth conditions: this appeared to occur in large cells which showed multiple spindle formation during nuclear division, a phenomenon apparently similar to the process of meiosis II during sporogenesis of Saccharomyces cerevisiae, but differing in that it produces diploid daughter nuclei by the vegetative process.
\end{abstract}

\section{INTRODUCTION}

Candida albicans is an imperfect yeast (Van Uden \& Buckley, 1970; McGinnis, 1980). Members of this species can be isolated from humans and animals, and are well known as opportunistic pathogens (Odds, 1979). This organism has been thought to exist in the haplophase (Sarachek et al., 1981); however, several recent studies have suggested that it is diploid. Magee and coworkers studied the isolation of auxotrophic mutants in C. albicans and concluded that auxotrophic markers existed in the homozygous state in these mutants, having segregated from a heterozygous state in the parents (Whelan et al., 1980). This finding and further investigations led them to conclude that this organism was diploid (Whelan \& Magee, 1981; Whelan \& Soll, 1982; Kakar et al., 1983). Poulter et al. (1981) also concluded from parasexual fusion experiments on C. albicans that tetraploidy or aneuploidy derived from diploid precursors could explain their results. Olaiya \& Sogin (1979) proposed after measurement of DNA content by flow cytometry that several $C$. albicans strains were diploid. Their argument was based on the similarity of the DNA content of this organism to that of diploid Saccharomyces cerevisiae strains. Sequence complexity, determined by reassociation kinetics, of DNA from several strains of this organism also supported the notion of diploidy (Riggsby et al., 1982). We have used fluorescence microscopy-photometry (FMP) to measure the DNA content of individual cells and simultaneously to correlate the content with cell morphology or stage of

† Present address: Department of Microbiology and Public Health, Giltner Hall, Michigan State University, East Lansing, MI 48824-1101, USA.

Abbretiations: FMP, fluorescence microscopy-photometry; NAO, nucleus-associated organelle. 
cell cycle in many clinical isolates of this organism (Suzuki et al., 1982). The majority of the isolates were found to be diploid but a few were haploid or tetraploid. We also proposed another criterion of ploidy based on the size of the nucleus-associated organelles (NAOs) (equivalent to spindle pole bodies) during spindle formation. This paper describes an isolate of $C$. albicans showing polyploidy (both diploid and tetraploid cells in a clonal culture) as determined by FMP and the dimensions of NAOs. These findings indicate that a shift of ploidy states can occur between diploid and tetraploid but not between haploid and diploid cells.

\section{METHODS}

Strains and cultivation. C. albicans strain NUM51 was isolated from a vaginal swab of a patient at ToyohashiShimin Hospital, Toyohashi-shi, Aichi Prefecture, Japan. The isolate developed chlamydospores on Dalmau plates and produced germ-tubes in serum, according to the methods described by McGinnis (1980). The sugar fermentation and assimilation profile was identical to that described by Van Uden \& Buckley (1970) for this species. C. albicans strain IFO1385, given to us by the Institute of Fermentation, Osaka, Japan, was derived originally from the type strain of this species, CBS562. Strain IAM4966 was obtained from the Institute of Applied Microbiology, The University of Tokyo, Bunkyo-ku, Tokyo, Japan. S. cerevisiae strains T26 $\alpha$ (haploid), T556 a $\alpha$ (diploid), and $30 \mathrm{~T}$ aa $\alpha \alpha$ (tetraploid) were used as reference strains for determining DNA content, as described previously (Suzuki et al., 1982). Yeast cells were grown in YM medium, consisting of 0.3\% yeast extract, $0.3 \%$ malt extract, $0.5 \%$ peptone and $1 \%$ glucose or in Basal Minimal synthetic (BM) medium $\left[0.5 \%\left(\mathrm{NH}_{4}\right)_{2} \mathrm{SO}_{4}, 0.02 \%\right.$ sodium citrate, $0.02 \% \mathrm{MgSO}_{4} .7 \mathrm{H}_{2} \mathrm{O}, 0.25 \% \mathrm{~K}_{2} \mathrm{HPO}_{4}, 0.5 \% \mathrm{NaCl}, 2 \%$ glucose and $0.0001 \%$ biotin]. When these media were solidified, $1.5 \%$ agar was added. Liquid cultures (50 to $100 \mathrm{ml}$ ) were incubated in $500 \mathrm{ml}$ Erlenmeyer flasks at $28^{\circ} \mathrm{C}$ with shaking. Cultures of $C$. albicans were starved by incubating with shaking in distilled water fo $24 \mathrm{~h}$. Stationary-phase cultures of $S$. cerevisiae were obtained after incubating yeast cells for 24 to $30 \mathrm{~h}$ in grow medium.

Growt heasurement. The optical density of a culture was measured with a Shimadzu QV-50 spectrophotometer using dilutions to an $\mathrm{OD}_{660}$ of $0 \cdot 1$ to $0 \cdot 2$. Cell counts were made in a Thoma counting chamber using samples which were fixed by the addition of an equal volume of $10 \%(\mathrm{v} / \mathrm{v})$ formaldehyde solution. The procedure used for counting yeast cells and their buds was that of Williamson \& Scope (1960).

Nuclear staining and fluorescence microscopy. The cells were stained with propidium iodide. The staining solution was a modified NS solution (Suzuki et al., 1982), consisting of $20 \mathrm{~mm}$-Tris/ $\mathrm{HCl}$ (pH 7.4), 0.25 M-sucrose, $7 \mathrm{mM}-2-$ mercaptoethanol, $0.4 \mathrm{~mm}$-phenylmethylsulphonyl fluoride, $1 \mathrm{mM}-\mathrm{Na}_{2} \mathrm{EDTA}, 1 \mathrm{~mm}-\mathrm{MgCl}_{2}, 0 \cdot 1 \mathrm{mM}-\mathrm{CaCl}_{2}$ and $0.005 \%(\mathrm{w} / \mathrm{v})$ chlorhexidine gluconate. Propidium iodide and RNAase A (Sigma) were added to the solution at final concentrations of $5 \mu \mathrm{g} \mathrm{m}^{-1}$ and $1 \mathrm{mg} \mathrm{ml}^{-1}$, respectively. The cells were washed with distilled water by centrifugation and suspended in the staining solution in a test tube. Chlorhexidine immediately killed the cells, which were instantaneously and homogeneously stained. The cell suspension was then incubated at $37^{\circ} \mathrm{C}$ for 3 to $5 \mathrm{~h}$ for complete digestion of RNA. Cell shapes and the DNA content of nuclei were observed simultaneously using an Olympus BH epifluorescence microscope equipped with phase objectives. The DNA content of individual nuclei was measured by using a Zeiss MPM03 FL photometer (Suzuki et al., 1982). Relative fluorescence was obtained on each nucleus with the microscope-photometer, and the fluorescence intensity was correlated to DNA content ( $\mathrm{fg}$ ) using haploid, diploid and tetraploid $S$. cerevisiae strains as references. The nuclear DNA content of a given culture was determined by measuring a random sample of 200 to 400 cells.

Ficoll density gradient centrifugation. Yeast cells were collected from YM media $(50 \mathrm{ml})$ by centrifugation and suspended in $5 \mathrm{ml}$ sterile distilled water. The cell suspension was then layered on a discontinuous density gradient consisting of $10 \mathrm{ml}$ each of $12,15,19$ and $23 \%(w / v)$ Ficoll 400 (Pharmacia). The gradient was centrifuged at $28^{\circ} \mathrm{C}$ in a swing-out rotor at $350 \mathrm{~g}$ for $5 \mathrm{~min}$.

Electron microscopy. Fixation of cells, staining and serial thin-sectioning were done according to Tanaka \& Hirata (1981). The specimens were observed in a Hitachi $\mathrm{H} 800$ electron microscope at an accelerating voltage of $100 \mathrm{kV}$. Electron micrographs were taken at magnifications between $\times 8000$ and $\times 10000$, and printed at $\times 40000$ for reconstructing three-dimensional images. Nuclear profiles in sectioned cells were outlined by hand onto tracing paper using nearby organelles as reference points to determine the position and continuity of the organelles. These tracing papers were matched through the subsequent sections with a set of markers and entered on a Kontron MOP-Videoplan, from which reconstructed profiles were obtained.

\section{RESULTS}

Characterization of colony formation and the mixture of cells of various sizes in some strains of C. albicans

Among 300 isolates of $C$. albicans that we obtained from clinical sources, three showed a characteristic heterogeneity of colony size on YM plates at an early stage of incubation: after 

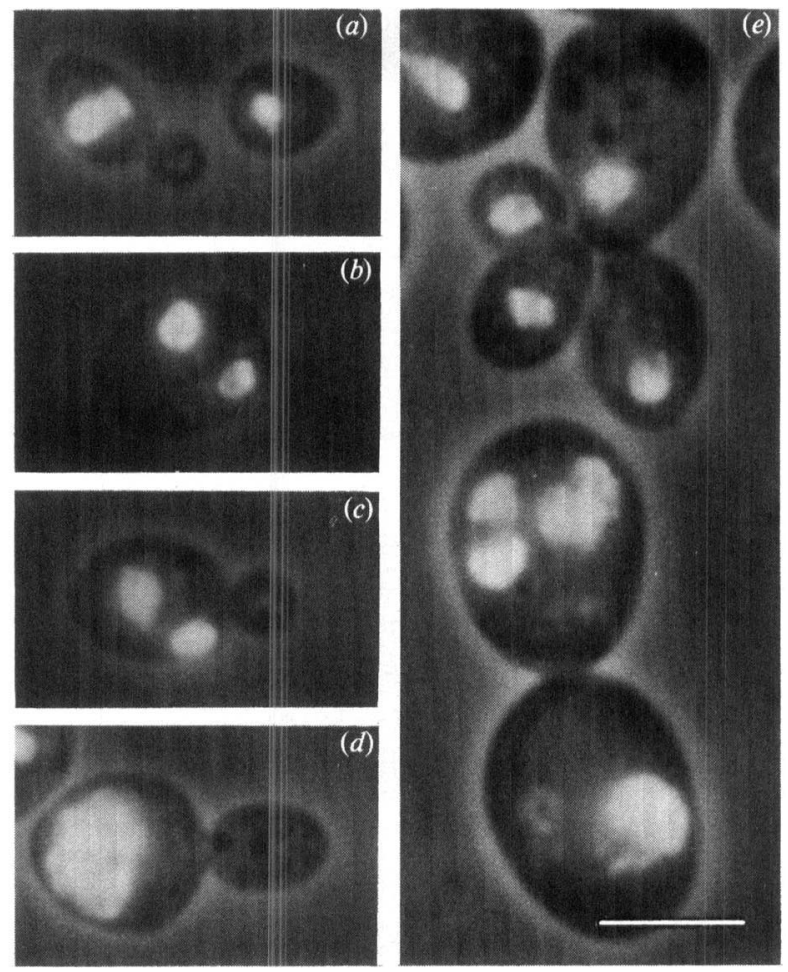

Fig. 1. Fluorescent and phase-contrast micrographs of cells of $C$. albicans NUM51. Small diploid cells $(a)$, binucleate $(b, c)$ and mononucleate $(d)$ cells were observed together with multinucleate and multiply-budded cells $(e)$. These cells were stained with propidium iodide. Bar, $5 \mu \mathrm{m}$.

incubation for $2 \mathrm{~d}$ at $28^{\circ} \mathrm{C}$, the colonies varied in size from $0.2 \mathrm{~mm}$ to $5 \mathrm{~mm}$. When one of the small colonies was re-streaked on another YM plate and incubated for $2 \mathrm{~d}$, the same mixture of colony sizes appeared. The large colonies behaved similarly. When these variously sized colonies were incubated for a further 2 to $3 \mathrm{~d}$, the small ones continued to increase in size; finally it became impossible to distinguish the large from the small. Photomicroscopy of suspended cells from the colonies revealed that the small colonies contained mainly aggregated cells with free cells as a minor fraction and the large ones consisted of a majority of free cells together with a minor fraction of aggregated cells. There were small and large yeast cells in both types of colonies. The small (S) cells, which accounted for about two-thirds of the total, were globose to ellipsoidal, and 2.5 to $3 \mu \mathrm{m}$ long. The large (L) cells were irregularly shaped, ellipsoidal to ovoid and occasionally pyriform or clavate. Twin-cell shaped or multiply-budded cells were also found (Fig. 1). The L cells were 3 to $6 \mu \mathrm{m}$ wide and 3 to $20 \mu \mathrm{m}$ long. It seemed possible that differentsized cells in these isolates were in different ploidy states; one of these three isolates, NUM51, was used for further investigations on ploidy.

\section{Determination of relative ploidy by FMP}

It was possible to estimate the DNA content of nuclei and thus to determine the relative ploidy by FMP. A calibration curve of nuclear DNA content against fluorescence intensity was obtained by using $S$. cerevisiae strains of known ploidy. Fig. 2 shows the profiles of fluorescence obtained from both exponential- and stationary-phase cells of haploid, diploid and tetraploid strains. The fluorescence values were calibrated by setting the gain of the photomultiplier to the approximate DNA content ( $\mathrm{fg}$ ) of the nuclei of reference strains. For example, the average fluorescence intensities of the stationary-phase cells of the haploid strain, T26, were used and the fluorescence value was adjusted to 18 , as the haploid DNA content of this organism is reported 


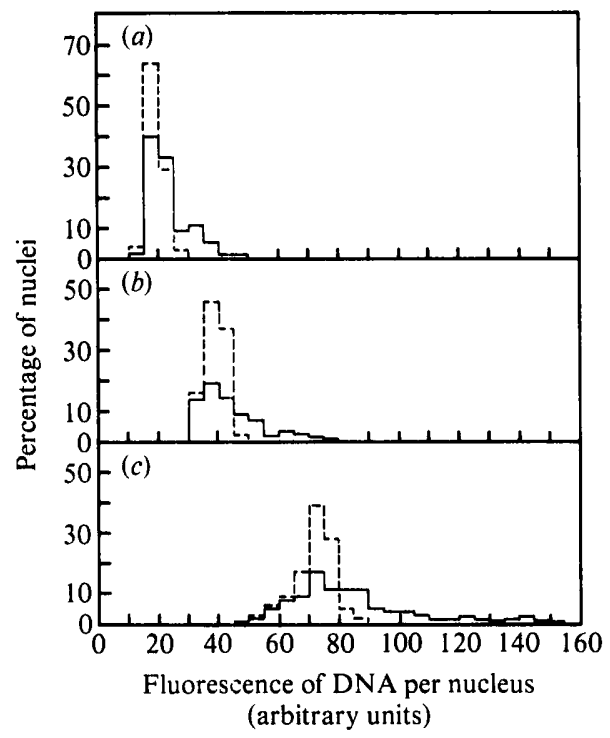

Fig. 2. Frequency distribution of DNA content of nuclei in $S$. cerevisiae cells of strains T26 (haploid, $a$ ), T556 (diploid, $b$ ) and 30T (tetraploid, $c$ ). The DNA contents of individual nuclei were determined by FMP of exponential-phase (solid lines) or stationary-phase (dashed lines) cultures.

to be $18 \mathrm{fg}$ (Riggsby et al., 1982). The average fluorescence of the nuclei of diploid and tetraploid strains was then determined. Once the gain setting was made, a round of measurements was carried out without further resetting, and the final calibration curve was obtained from the data of the average intensities of haploid, diploid and tetraploid $S$. cerevisiae, assuming the DNA content of their G-1 phase nuclei to be 18,36 and $72 \mathrm{fg}$.

Two strains of $C$. albicans, IAM4966 and IFO1385, were examined together with NUM51. Strain IAM4966, considered a typical strain of this organism, produced yeast cells 2.5 to $3 \mu \mathrm{m}$ wide and 2.5 to $4 \mu \mathrm{m}$ long, similar in size to the S cells of NUM51. The DNA content of IAM4966 ranged from about 30 to $70 \mathrm{fg}$ (Fig. $3 a$ ), and was similar to that of the diploid $S$. cerevisiae. Strain IAM4966 was therefore assumed to be diploid. Strain IFO1385 comprised yeast cells larger than those of IAM4966, 3 to $5 \mu \mathrm{m}$ wide and 3 to $10 \mu \mathrm{m}$ long. The DNA content of IFO1385 ranged from 60 to $160 \mathrm{fg}$ (Fig. $3 \mathrm{c}$ ). This profile of DNA content distribution was similar to that of a tetraploid $S$. cerevisiae strain. When the DNA content of starved cultures was measured, a single peak appeared around 35 to $40 \mathrm{fg}$ in IAM4966 and around $70 \mathrm{fg}$ in IFO1 385 (Fig. $3 a, c$ ). Thus, IFO1385 was assumed to be tetraploid or near tetraploid. The DNA distribution profile of NUM51 was much broader than those of the other two strains from 30 to $200 \mathrm{fg}$ (Fig. $3 \mathrm{~b}$ ). When a culture of this strain was starved, two peaks with maxima around $35 \mathrm{fg}$ and $70 \mathrm{fg}$, respectively, were observed (Fig. $3 \mathrm{~b}$ ). Further starvation, up to $72 \mathrm{~h}$, did not change the profile. An experiment was done to separate exponential-phase cells of NUM51 (Fig. $4 b$ ) into an S-cell-rich fraction (on the boundary between the 12 and $16 \%$ Ficoll layers) and an L-cellrich one (between the 19 and $23 \%$ layers) (Fig. $4 a, c$, solid lines). Cultures of each of these fractions were starved (Fig. $4 a, c$, dashed lines). The S-cell-rich fraction gave rise to cells with about $35 \mathrm{fg}$ DNA and the L-cell-rich fraction to cells with about $70 \mathrm{fg}$ DNA. Thus, the differences in size among cells of NUM51 seemed to be related to the difference in DNA content and that difference seemed to reflect the presence of two different ploidy states, diploid and tetraploid. The ploidy state of this strain was tentatively termed polyploid.

\section{Evaluation of polyploidy of strain NUM5I by measuring the diameter of NAOs}

The ploidy of a cell can be determined by counting chromosome number, but countable chromosomes cannot be seen in C. albicans at any time in its life cycle. In our previous work, we 


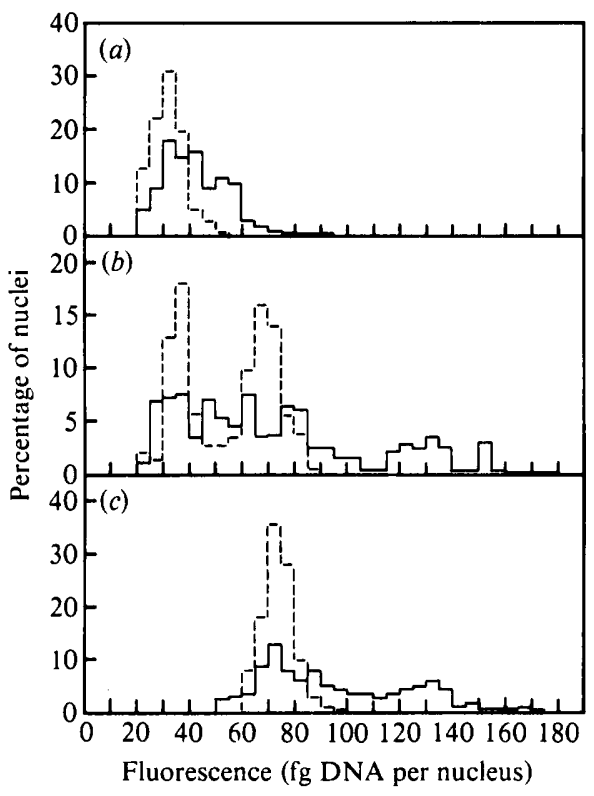

Fig. 3

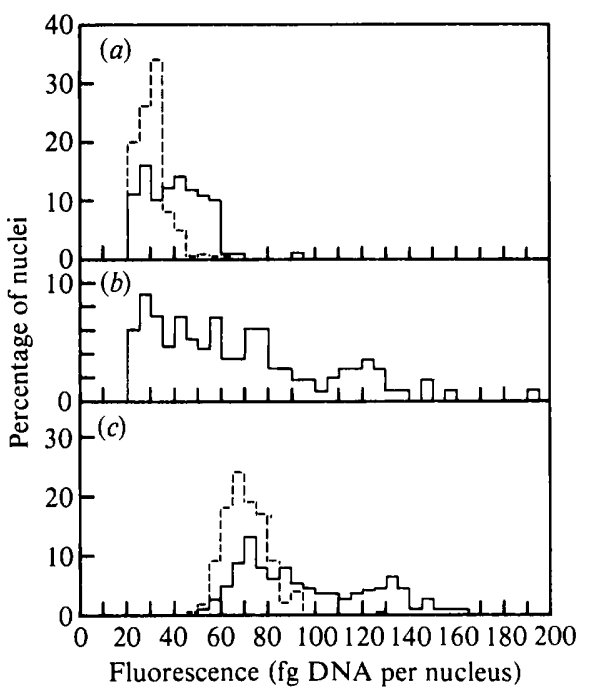

Fig. 4

Fig. 3. Frequency distribution of DNA content of nuclei in C. albicans cells of strains IAM4966 (a), NUM51 $(b)$ and IFO1385 (c). The DNA contents of individual nuclei were determined by FMP of exponential-phase (solid lines) or starved (dashed lines) cultures.

Fig. 4. Frequency distribution of DNA content of nuclei in a fractionated culture of $C$. albicans NUM51. An exponential-phase culture $(b)$ was fractionated into two fractions, the S-cell-rich fraction ( $a$, solid line) and the L-cell-rich fraction $(c$, solid line) by Ficoll density gradient centrifugation. Cultures of the two fractions were then starved (dashed lines in $a$ and $c$ ).

used another criterion, the dimension of NAOs, as an indicator of ploidy in this organism (Suzuki et al., 1982). Observations by serial thin-sectioning electron microscopy revealed the presence of NAOs on the nuclear membrane. We measured the diameter of the NAOs which constituted the spindle poles in a dividing nucleus. The diameter of NAOs in IAM4966 was $120 \pm 14 \mathrm{~nm}$ (mean $\pm \mathrm{SD}$ ), and in IFO1385, $210 \pm 25 \mathrm{~nm}$. In NUM51, two classes of NAOs were found, with mean diameters of $118 \pm 13 \mathrm{~nm}$ and $196 \pm 15 \mathrm{~nm}$, respectively, Thus by this criterion also, NUM51 seemed to exist in two different states, diploid and tetraploid.

\section{Diphasic growth caused a shift in ploidy state in strain NUM5I}

Since in the polyploid strain, the size of individual cells appeared to reflect their ploidy, we considered whether the ploidy state could be experimentally changed by altering the cell size. When cells of NUM51 were transferred from YM to BM medium, the growth curve was diphasic (Fig. 5), with a doubling time of $2.5 \mathrm{~h}$ (as determined by $\mathrm{OD}_{660}$ ) during the first phase, and of $5 \mathrm{~h}$ during the second phase, which started $4 \mathrm{~h}$ after the transfer of the culture. The increases in the cell number and nuclear DNA content of the culture showed different kinetics, with DNA initially lagging behind cell number or $\mathrm{OD}_{660}$. Four different types of cells appeared during the diphasic growth; these were called SI, SII, LI and LII. As observed under a fluorescence microscope-photometer with a phase-contrast objective, type SI cells were mononucleate and had a nuclear DNA content lower than $80 \mathrm{fg}$. Budded SI cells contained about $80 \mathrm{fg}$ DNA, and those without buds about $40 \mathrm{fg}$. Thus, type SI cells were probably diploid cells. Type SII cells were doublets with two nuclei, each containing 35 to $40 \mathrm{fg}$ DNA. One nucleus of a type SII cell was usually found in the mother cell and the other in the daughter cell, but some cells had the two nuclei in either one of the two cells. Type LI cells were mononucleate 


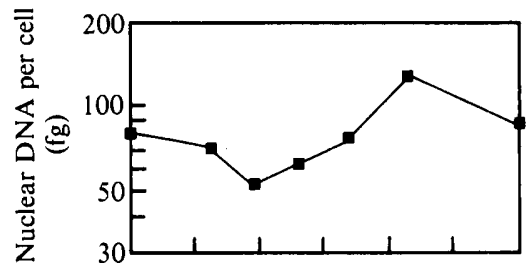

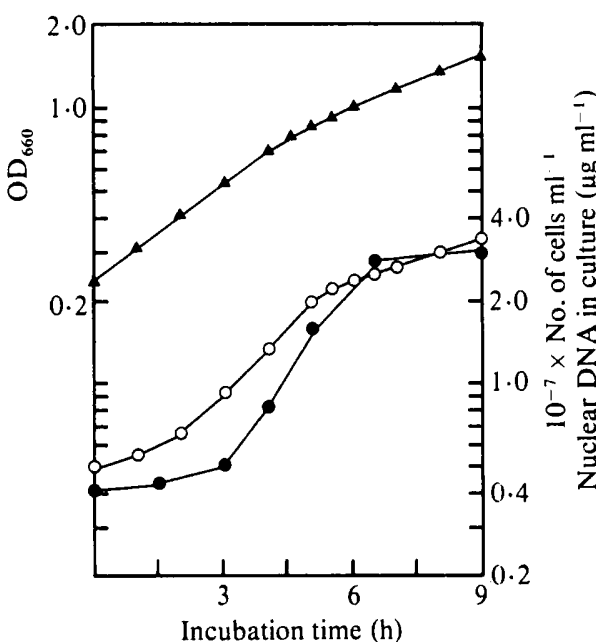

Fig. 5

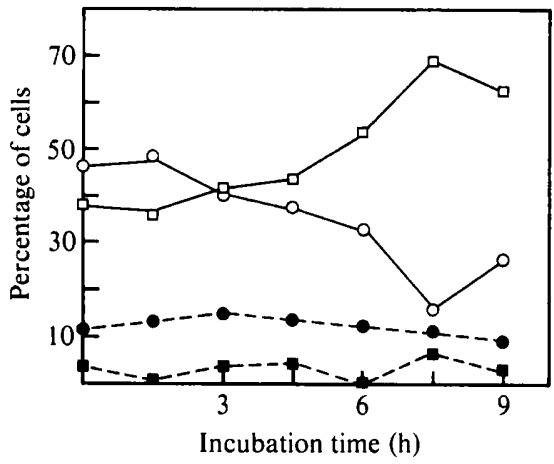

Fig. 6

Fig. 5. Diphasic growth of $C$. albicans NUM51 cultivated in BM medium after transfer from YM medium. Cell number $(O)$ was determined by using a Thoma counting chamber. Nuclear DNA content of the culture (O) was calculated by multiplying the cell number by the mean nuclear DNA content per cell measured by FMP ( $\mathbf{\square}) . \Delta, \mathrm{OD}_{660}$.

Fig. 6. Changes in the percentage of various cell types during diphasic growth of $C$. albicans NUM51 as described in Fig. 5. Cells were classified as type SI (O), type LI ( $\square$ ), type SII (O) and type LII ( $\square$ ), according to the data from individual cells on the number of nuclei and their DNA content, measured by FMP.

large cells with more than $90 \mathrm{fg}$ DNA. A type LI cell with a DNA content around $90 \mathrm{fg}$ was unbudded and was clearly distinguishable from a type SI cell with a bud. Budded LI cells (these frequently had multiple buds) had a nucleus with a DNA content of 120 to $150 \mathrm{fg}$. LI cells were apparently tetraploid. Type LII cells were multiply-budded and bi-, tri- or tetranucleate, and had a total DNA content of more than $140 \mathrm{fg}$. They could therefore be easily distinguished from type SII cells. A marked change in the percentage of each cell type occurred after $5 \mathrm{~h}$ incubation of the transferred culture. Type LI cells increased, with a concurrent decrease in SI cells; 7 to $8 \mathrm{~h}$ after the transfer of the culture, $70 \%$ of the cells in the culture were type LI (Fig. 6). After $5 \mathrm{~h}$ incubation, the diameter of mitotic NAOs had changed from that of diploid cells to that of tetraploid cells (Fig. $7 a-c$ ). The maximum percentage of tetraploid NAOs was observed at around $5 \mathrm{~h}$. This time corresponded to the inflection point of the growth curve and also to the time when the rate of DNA synthesis dropped (Fig. 5). The net increase in DNA content per cell almost ceased at 6.5 to $7 \mathrm{~h}$ after the transfer; at this time the percentage of diploid NAOs increased, with a concurrent decrease in tetraploid ones (Fig. 5, Fig. 7d,e). We infer that the culture underwent two ploidy shifts during diphasic growth: first from diploid to tetraploid and then from tetraploid to diploid. In neither of the control strains, diploid IAM4966 and tetraploid IFO1385, did changes occur in the size of the NAOs. The shift in ploidy thus seems to be due to the polyploid nature of strain NUM51. 


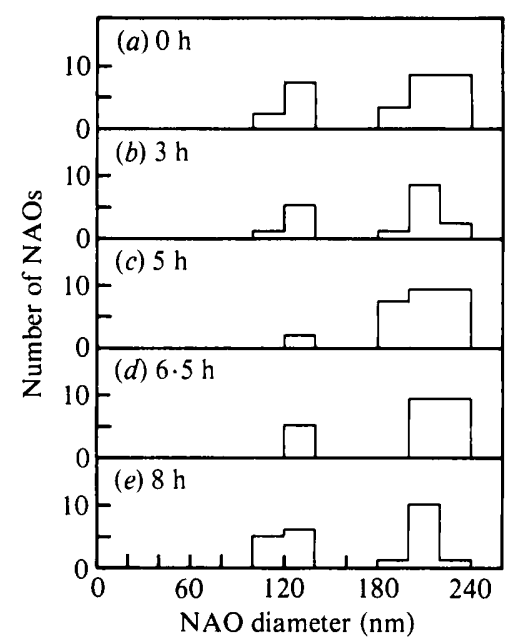

Fig. 7. Size distribution of NAOs in C. albicans NUM51 at various times during diphasic growth as described in Fig. 5. NAO diameters were estimated on cells randomly sampled at a given time by serial thin-sectioning electron microscopy.

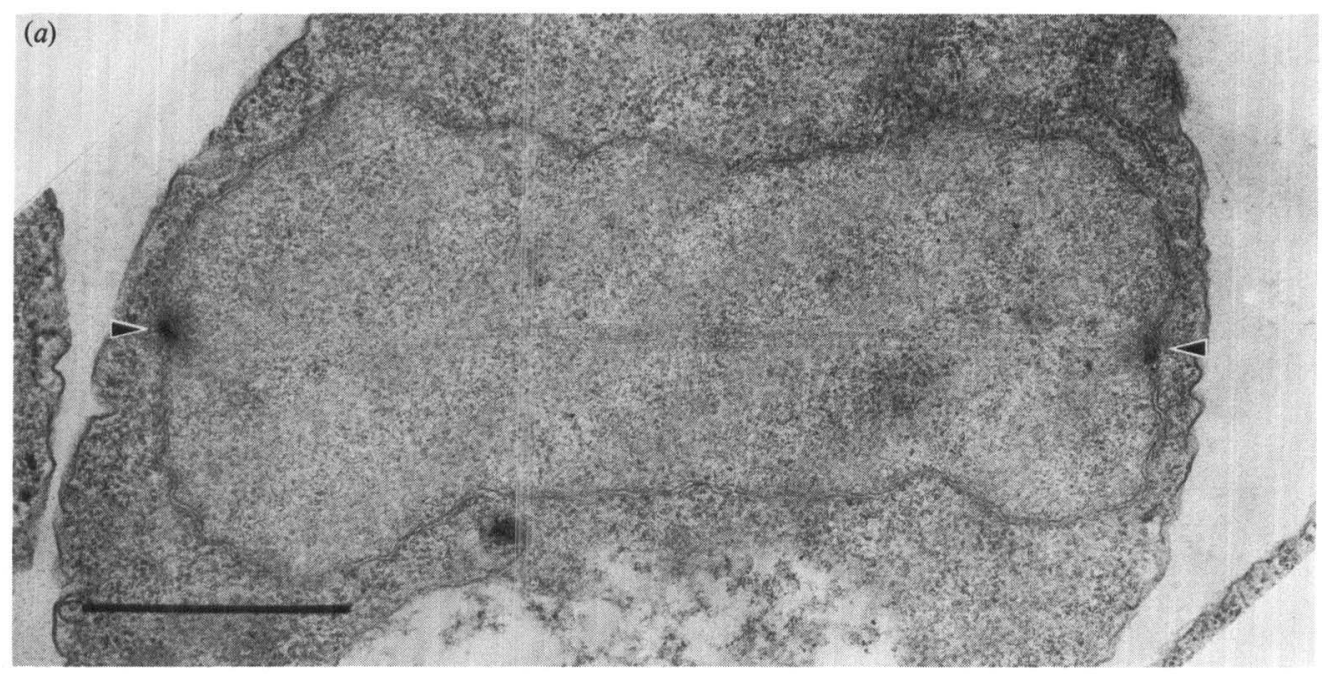

(b)

(c)
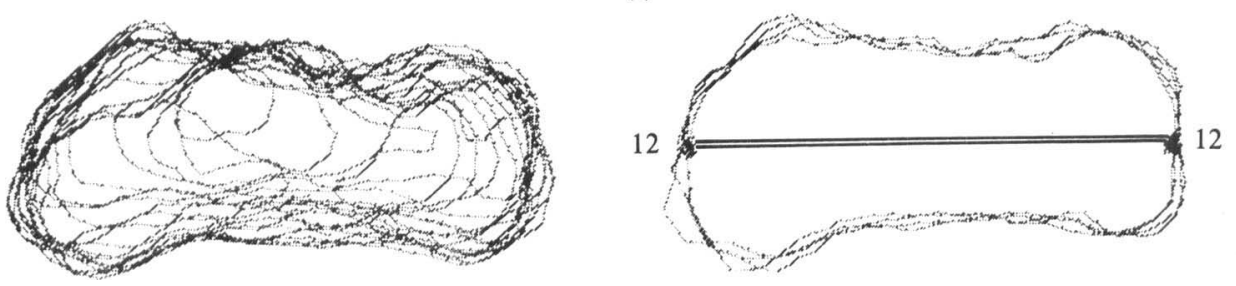

Fig. 8. Nuclear profile and a spindle in a mononucleate cell (type I, see text) of $C$. albicans NUM51. A thin section revealed a spindle with a pair of NAOs $(a)$. The diameter of the NAOs (arrowed) was around $120 \mathrm{~nm}$, showing diploidy of this nucleus. $(b)$ Three-dimensional reconstituted image of the nucleus. $(c)$ The portion of the nucleus showing the spindle. The numbers in image $(c)$ indicate the number of sections in which the NAOs appeared. A total of 19 sections was required to observe the nucleus. Bar, $1 \mu \mathrm{m}$. 

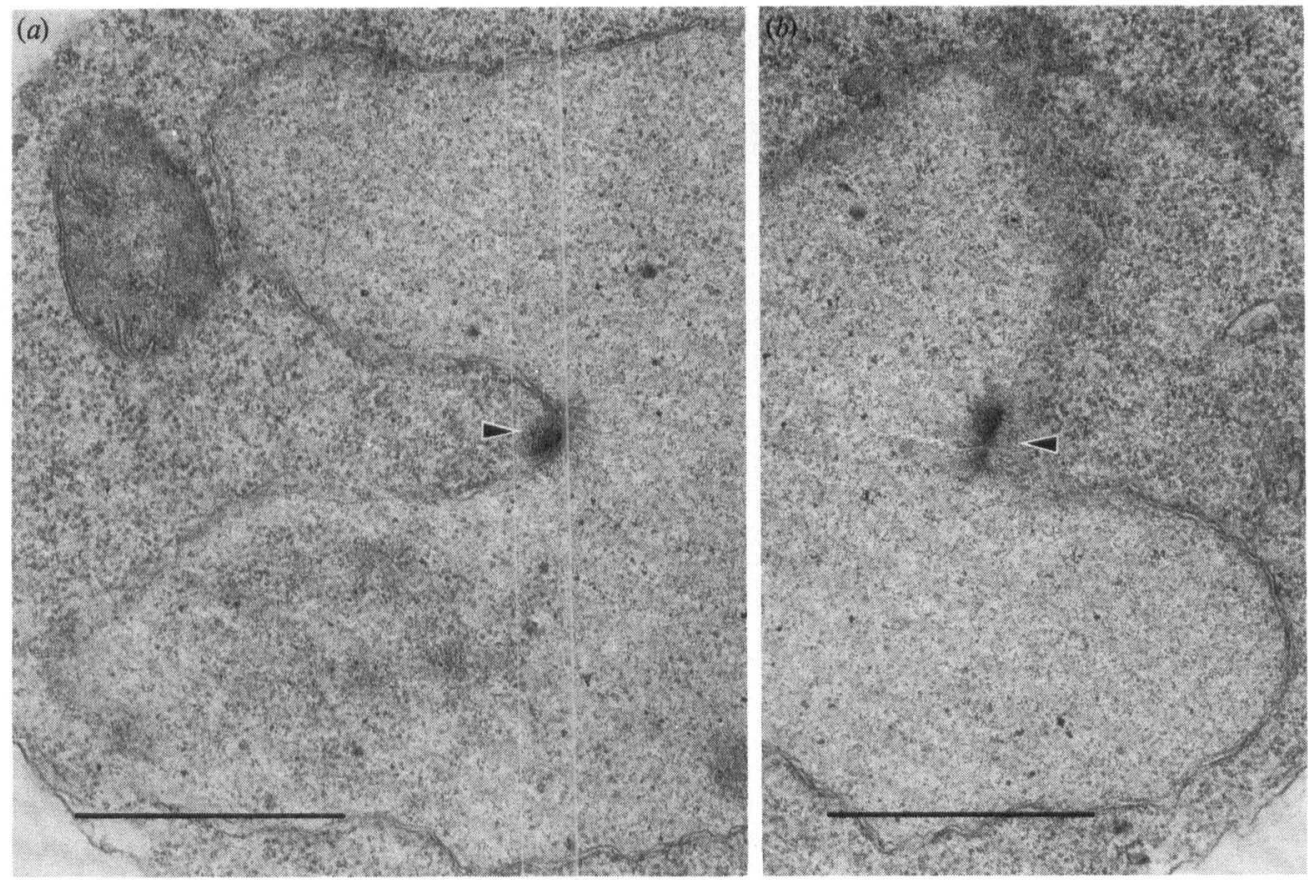

(c)

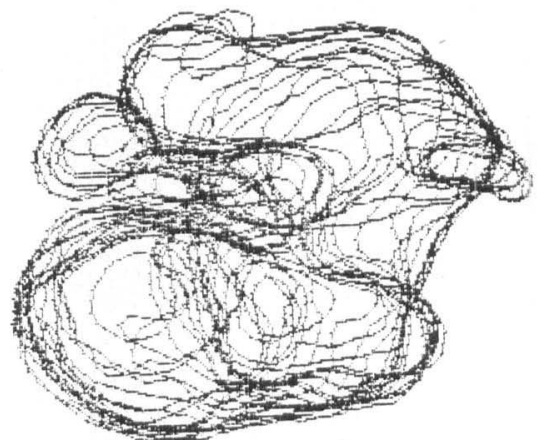

(d)

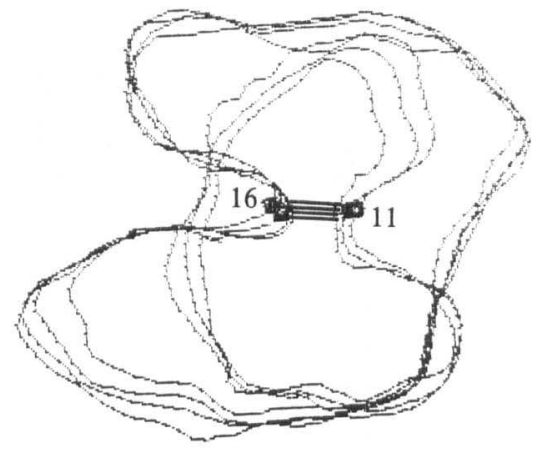

Fig. 9. Spindle formation of a mononucleate large cell (type II, see text) of C. albicans NUM51. Each of the pair of NAOs in a spindle is shown in $(a)$ and $(b)$ (arrowed). Their diameter was $200 \mathrm{~nm}$, indicating this nucleus to be tetraploid. $(c)$ Three-dimensional reconstructed image of the nucleus. $(d)$ The portion of the nucleus showing the sites of NAOs. The numbers in $(d)$ indicate the number of sections in which the NAOs appeared. A total of 34 sections was required to observe the nucleus. Bars, $1 \mu \mathrm{m}$.

\section{Electron microscopic observations on spindle formation in strain NUM5I}

Spindle formation is a landmark event of mitosis in yeast cells (Byers \& Goetsch, 1975). We studied the cytological features of nuclear division in the polyploid strain NUM51. Cells of a culture undergoing diphasic growth were serial-sectioned for electron microscopy and all the sections of several cells undergoing spindle formation were examined. Nuclear profiles of individual cells were reconstructed in a Kontron Videoplan to give the three-dimensional shape of the nucleus. Representative results are shown in Figs 8 to 10. The cells were classified into the following four types: type I cells were mononucleate and had a pair of NAOs facing each other with a spindle (Fig. 8). These NAOs were around $120 \mathrm{~nm}$ in diameter, and the nucleus was therefore assumed to be diploid. We propose that type I cells correspond to type SI cells as 
(a)
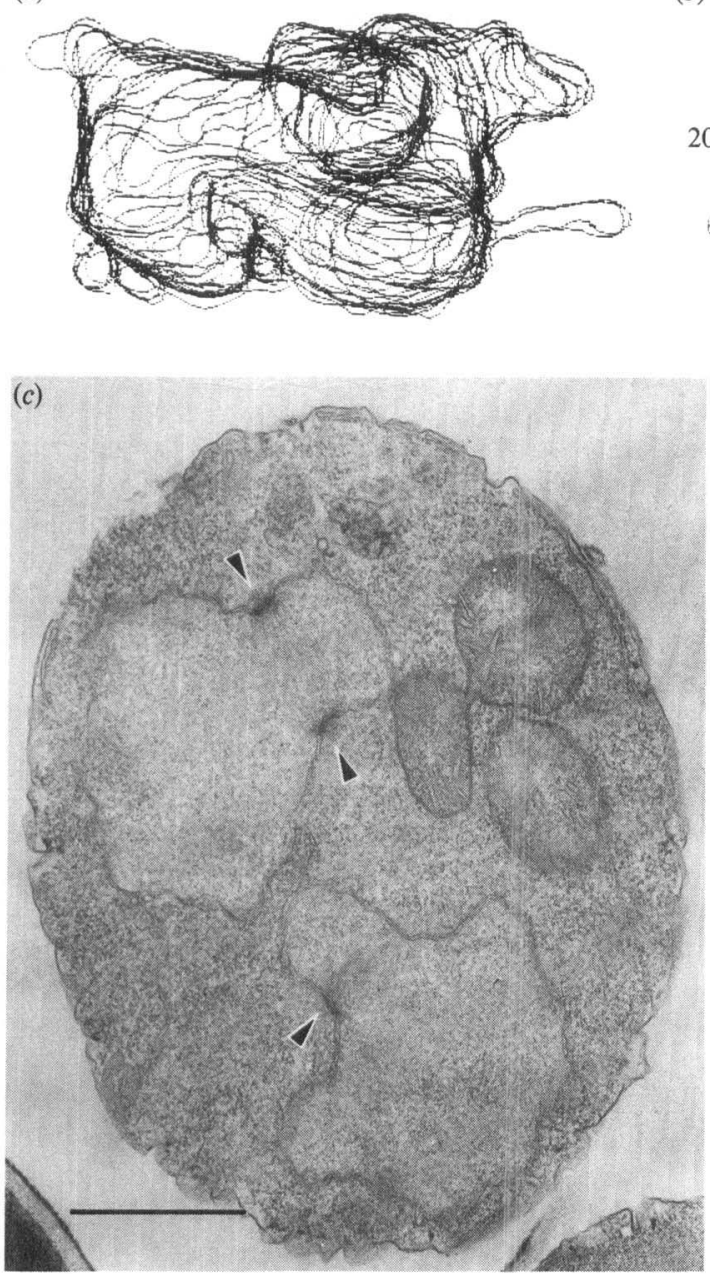

(b)

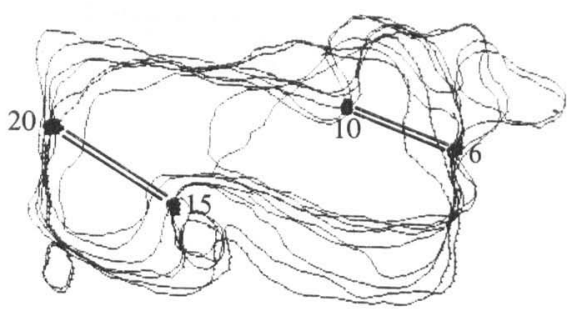

(d)

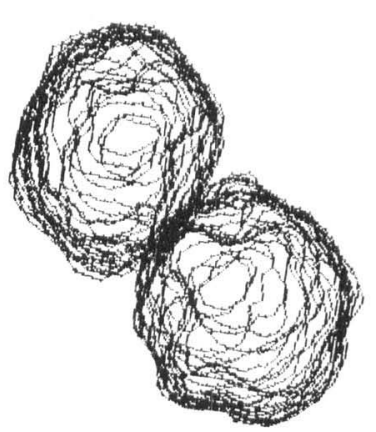

(e)

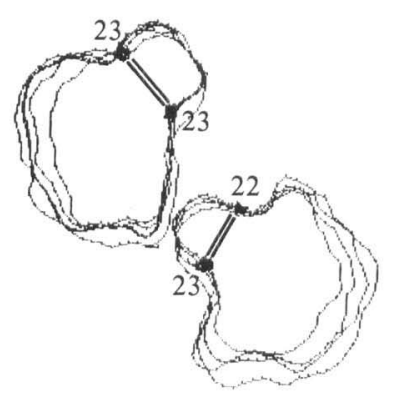

Fig. 10. Multiple spindle formation in large cells of $C$. albicans NUM51. (a) Three-dimensional reconstructed image of the nucleus of a mononucleate large cell (type III, see text). (b) The sites of NAOs and spindles in this nucleus. Some of the large cells were binucleate (type IV, see text); $(c)$ is a section showing two nuclei in such a cell. The arrows indicate NAOs, of diameter around $120 \mathrm{~nm}$, equivalent to diploid ones. $(d)$ Three-dimensional reconstructed image of the two nuclei in $(c)$. $(e)$ The sites of NAOs in these nuclei. The numbers in $(b)$ and $(e)$ indicate the number of sections in which the NAOs appeared. A total of 38 sections was required to observe the nucleus in $(a)$, and a total of 30 to observe the two nuclei in $(d)$. Bar, $1 \mu \mathrm{m}$.

defined previously by fluorescence microscopy. Type II cells had a single nucleus containing a pair of large NAOs, around $200 \mathrm{~nm}$ in diameter (Fig. 9). Since type II cells thus appeared to be tetraploid, they correspond to the LI cells defined by fluorescence microscopy. Type III cells were mononucleate but had two spindles, each of which was composed of a pair of NAOs of around $120 \mathrm{~nm}$ in diameter (Fig. $10 a, b$ ); they were taken to be members of the type LI class. In terms of DNA content, the type III cell is assumed to be tetraploid; in terms of genome size inferred from the NAO dimensions, the single nucleus contains two diploid genomes. Type IV cells had two nuclei, each containing a spindle with a pair of NAOs of $120 \mathrm{~nm}$ in diameter (Fig. $10 c-e$ ). This indicated that type IV cells corresponded to the LII group as defined by fluorescence microscopy. 


\section{DISCUSSION}

It should be emphasized that the terms 'diploid' and 'tetraploid', as defined from DNA content determined by FMP, refer respectively to cells having a DNA content of $2 \mathrm{C}$ to $4 \mathrm{C}$ or $4 \mathrm{C}$ to $8 \mathrm{C}$, where $1 \mathrm{C}$ indicates the haploid level of DNA. This criterion of ploidy determination cannot definitively answer the question whether the various cell types, especially type LI, actually represent different states of ploidy rather than simply subpopulations with a prolonged G-2 stage. The ideal way to determine the ploidy would be to count the number of metaphase chromosomes, as has been done for many eukaryotes (Brodsky \& Uryvaeva, 1977), but unfortunately, the chromosomes of most yeast cells are undetectable (Byers \& Goetsch, 1975; Phaff et al., 1978). We therefore used another criterion of ploidy, namely the size of NAOs during the formation of spindles. By this criterion, the type LI cells of NUM51, which had a tetraploid level of DNA, were further classified into two types; one was mononucleate with a tetraploid genome and the other was mononucleate with two diploid genomes. The latter cells could only be discriminated from the former by observing the ultrastructure of NAOs and spindles. It is, however, possible that a prolonged G-2 stage may be the trigger that brings about the shift of ploidy states in this strain.

One of the possible mechanisms of the shift-up of ploidy, from diploid to tetraploid, in this strain might be karyogamy. If karyogamy were the major event that created tetraploidy in this polyploid strain, one might expect that binucleate cells would appear as a result of acytokinetic mitosis, and that then the two nuclei would fuse. However, the results obtained from the study of diphasic growth of this strain showed no significant variation in the percentage of such binucleate cells preceding the shift-up of ploidy (Fig. 6). Thus, karyogamy appears to be excluded in this strain as the major event causing the increase in ploidy during diphasic growth, which probably resulted from the occurrence of chromosome duplication in the absence of both nuclear division and budding. Ploidy increase was observed when the cells underwent nuclear DNA synthesis more rapidly than increase in cell number (Fig. 5). This observation corresponds to the notion of 'endomitosis' in the yeast life cycle (Phaff et al., 1978). The phenomenon of endomitosis or endopolyploidization (Brodsky \& Uryvaeva, 1977) occurs as a consequence of the blocking of the normal course of mitosis or the omission of certain phases in the nuclear division cycle of eukaryotic cells. In NUM51, the shift-up of ploidy was associated with an increase in the dimension of NAOs (Fig. 7). The increase in the frequency of occurrence of tetraploid nuclei during the first period of diphasic growth means that some of the large tetraploid cells should be derived from a diploid ancestral cell. Thus, in terms of NAO structure, one could hypothesize that, in the process of shift-up of ploidy, genomes were made to duplicate without segregation, resulting in the production of enlarged or 'endoduplicated' NAOs. When endoduplication did not occur, a given cell would remain diploid or tetraploid, depending on the previous state. Therefore, in the many other strains of this organism, a control mechanism may exist that prevents NAOs from 'endoduplication' and maintains a diploid state.

The shift-down of ploidy, from tetraploid to diploid, was found in this strain when nuclear division and cell division proceeded without a significant increase in the DNA content per cell (Fig. 5). During this period, small daughter buds were produced from large mother cells. At least three mechanisms for this ploidy reduction could be envisaged: a meiotic reduction, a progressive loss of chromosomes, or a vegetative reduction division. There was no cytological evidence for a meiotic reduction. The possibility of a piecemeal loss of chromosomes from tetraploid nuclei by non-disjunction or other means has been suggested for $C$. albicans: instability of the ploidy state and the occurrence of aneuploid segregants were reported for the tetraploid fusion products of this organism (Kakar et al., 1983; Whelan et al., 1985). In the present case, the state of diploidy would be preceded by transitory aneuploidy lasting over generations and one could also expect that some nuclei might show a DNA content below the diploid level. However, no nuclei with less than the diploid amount of DNA were found in strain NUM51 during diphasic growth. Persistent aneuploidy would lead to a distribution profile of DNA content containing either intermediate peaks between $2 \mathrm{C}$ and $4 \mathrm{C}$ or a pattern of broad distribution. However, the results showed two main peaks, around $2 \mathrm{C}$ and $4 \mathrm{C}$, respectively (Fig. 4), which does not support the idea that piecemeal loss of chromosomes is a major event during 
the process of reduction in ploidy state. The third mechanism, a vegetative reduction division, seems most plausible, because of the multiple spindle figures that were found in the large cells of this strain (Fig. 9). Each pair of diploid NAOs would presumably give rise to diploid daughter nuclei. This type of spindle figure is similar to that found in meiosis II during ascospore development of $S$. cerevisiae (Moens \& Rapport, 1971); however, there was no other cytological evidence in NUM51 of such meiotic ícatures as structures relating to sexual spore development or the formation of synaptonemal complexes.

The findings on the polyploid strain of $C$. albicans in this study will contribute to the problems of ploidy variance in this species.

We thank S. Nishibayashi and members of the Analytical Center of NIBB for assistance with FMP. We are grateful to Eiko Seiki Sangyo Co. for use of the Kontron Videoplan. We also thank Paul T. Magee and members of his laboratory at Michigan State University for their interest and fruitful discussions. This study was supported by Grants-in-Aid for Scientific Research nos 58480018 and 58740295 from the Ministry of Education, Science and Culture of Japan.

\section{REFERENCES}

Brodsky, W. Y. \& URyvaeva, I. V. (1977). Cell polyploidy: its relation to tissue growth and function. International Review of Cytology 50, 275-332.

ByERS, B. \& GOETSCH, L. (1975). Behavior of spindle and spindle plaques in the cell cycle and conjugation of Saccharomyces cerevisiae. Journal of Bacteriology 152, 511-523.

Kakar, S. N., Partridge, R. M. \& Magee, P. T. (1983). A genetic analysis of Candida albicans: isolation of a wide variety of auxotrophs and demonstration of linkage and complementation. Genetics 104, 241-255.

McGinNIs, M. R. (1980). Laboratory Handbook of Medical Mycology. New York: Academic Press.

MoEns, P. B. \& RAPPORT, E. (1971). Spindles, spindle plaques, and meiosis in the yeast Saccharomyces cerevisiae (Hansen). Journal of Cell Biology 50, 344361.

ODDs, F. C. (1979). Morphogenesis in Candida with special reference to $C$. albicans. In Candida and Candidosis, pp. 29-41. Edited by F. C. Odds. Leicester: Leicester University Press.

OlaiYa, A. F. \& Sogin, S. J. (1979). Ploidy determination of Candida albicans. Journal of Bacteriology 140, 1043-1049.

PhafF, H. J., Miller, M. W. \& Mrak, E. M. (1978). The Life of Yeasts. Cambridge, Mass.: Harvard University Press.

Poulter, R., Jeffery, K., Hubbard, M. J., ShepHeRD, M. G. \& Sullivan, P. A. (1981). Parasexual genetic analysis of Candida albicans by spheroplast fusion. Journal of Bacteriology 146, 833-840.

Riggsby, W. S., Torres-BauzA, L. J., WiLls, J. W. \& TOWNES, T. M. (1982). DNA content, kinetic complexity, and the ploidy question in Candida albicans. Molecular and Cellular Biology 2, 853-862.
SARaCheK, A., Roads, D. F. \& Schwarzhoff, R. H. (1981). Hybridization of Candida albicans through fusion of protoplasts. Archives of Microbiology 129, 1-8.

Suzuki, T., Nishibayashi, S., Kuroiwa, T., Kanbe, T. \& TANAKA, K. (1982). Variance of ploidy in Candida albicans. Journal of Bacteriology 152, 893-896.

Tanaka, K. \& Hirata, A. (1981). Ascospore development in the fission yeasts Schizosaccharomyces pombe and $S$. japonicus. Journal of Cell Science 56, 263-279.

Whelan, W. L. \& Magee, P. T. (1981). Natural heterozygosity in Candida albicans. Journal of Bacteriology 145, 869-903.

Whelan, W. L. \& Soll, D. R. (1982). Mitotic recombination of Candida albicans: recessive lethal alleles linked to a gene required for methionine biosynthesis. Molecular and General Genetics 187, 477-485.

Whelan, W. L., Partridge, R. M. \& Magee, P. T. (1980). Heterozygosity and segregation in Candida albicans. Molecular and General Genetics 180, 107 113.

Whelan, W. L., Markie, D. M., Simpkin, K. G. \& POUlter, R. M. (1985). Instability of Candida albicans hybrids. Journal of Bacteriology 161, 11311136.

Williamson, D. H. \& Scope, A. W. (1960). The behaviour of nucleic acids in synchronously dividing culture of Saccharomyces cerevisiae. Experimental Cell Research 20, 338-349.

VAN UdEN, N. \& BUCKLEY, H. (1970). Genus 2. Candida Berkhout. In The Yeasts, pp. 893-1087. Edited by J. Lodder. Amsterdam: North-Holland Publishing Co. 